\title{
Penggunaan Variasi Media Ajar Terhadap 3 Gaya Belajar Siswa dalam Pembelajaran Bahasa Jepang
}

\author{
Murni Setianingrum \\ SMA Korpri Bekasi \\ Jl. Rumah Sakit Mekar Sari Bekasi Timur 17112, Indonesia \\ e-mail: murnisetianingrum@gmail.com \\ phone: +62-878-8556-7864
}

\begin{abstract}
Abstraksi
Mengajar membutuhkan metode pengajaran yang kreatif dan penggunaan media ajar yang kreatif sehingga ilmu yang disampaikan dapat di terima dengan baik oleh siswa. Kemampuan anak dalam menangkap materi ajar tergantung dari gaya belajarnya. Gaya belajar adalah kombinasi dari menyerap, mengatur, dan mengolah informasi. Ada 3 gaya belajar yang di jelaskan dalam Quantum Learning, yaitu Audio, visual, dan kinestetik. Gaya belajar visual adalah gaya belajar dengan melalui indera penglihatannya. Media ajar yang sesuai untuk gaya belajar visual adalah berupa gambar, grafik, ilustrasi, slide dan tulisan yang berwarna-warni. Gaya belajar auditori adalah gaya belajar melalui indera pendengarannya. Media ajar yang sesuai untuk gaya belajar auditori adalah berupa video, rekaman suara, dan pola bercerita dengan bunyi, irama, dan nada. Gaya belajar kinestetik adalah gaya belajar melalui bergerak, menyentuh, dan melakukan sesuatu yang memberikan informasi tertentu agar dia dapat mengingatnya. Media ajar yang sesuai untuk gaya belajar kinestetik adalah dengan alat bantu peraga. Dalam penyampaian materi tiap tatap muka di mulai dengan memberikan motivasi yang berfokus untuk 3 gaya belajar siswa. Kemudian di lanjutkan dengan pengenalan materi dan penyampaian materi dengan menggunakan variasi media ajar sehingga materi dapat tersampaikan dengan baik kepada 3 gaya belajar siswa tersebut. Di akhir pelajaran pada saat memainkan role play diperlukan teknik role play yang memiliki aturan permainan yang mengkombinasikan 3 gaya belajar sehingga semua dapat memainkannya. Setelah bermain role play untuk mengetahui kepemahaman siswa lebih lanjut lagi dapat dilakukan post tes. Soal post tesnya pun dibuat dan disesuaikan untuk 3 gaya belajar sekaligus. Diharapkan dengan pemahaman guru tentang gaya belajar siswa, guru dapat lebih kreatif dalam pengajaran maupun dalam pembuatan media ajar. Apabila siswa termotivasi untuk belajar maka minat belajar terhadap pelajaran bahasa Jepang akan meningkat.
\end{abstract}

\section{Kata Kunci: Media Ajar; Gaya Belajar, Quantum Learning}

Abstract
Teaching requires creative methods and variety of teaching media in order students able to
absorb the lesson. Teacher shouldn't force a certain method to a group of student. Because each
student has different way of absorbing the lesson, depends on his/her learning style. Learning
style is a combination of absorbing, organizing, and processing information. There are three (3)
types of learning styles described in Quantum Learning; Visual, Audio, and Kinesthetic.
Visual learning style is a method focusing on visual sight. The suitable teaching media for visual
learning style is through pictures, graphics, illustration, slides, and full-colored fonts or drawing.
Audio learning style is a method focusing on hearing sense. The suitable teaching media for
audio learning style may includes video, tape recording, story-telling using sounds, rhythm, and
variety of tones. Kinesthetic learning style is a method focusing on movement, sense of touch,


and informative activity. Suitable media for this learning style is by using visual teaching aids. In delivering the lesson, we should start the class by giving motivation focusing on the three (3) different learning styles. Then continue with lesson's introduction, followed by the main lesson delivery, using variation of learning media to be able to reach students with three (3) types of learning styles. At the end of the lesson, conduct role play which applies certain techniques of steps and regulation combining the three (3) learning styles. Finally, after role play activity, we may close the lesson by evaluating students' understanding. It's also better to custom-made the evaluation test problems based on the three (3) learning styles. It is expected that with the wholemapping of teachers' understanding on students' learning styles, teachers can be more creative in delivering the lesson and also in creating teaching media. If students are motivated to learn then they also will have more interest toward Japanese Language learning.

\section{Keyword: Teaching Media; Learning Style, Quantum Learning}

\section{Pendahuluan}

Mengajar bukanlah hal sekedar menyampaikan materi ajar. Mengajar membutuhkan Metode. Tentu saja metode mengajar harus kreatif sehingga ilmu yang disampaikan dapat di terima dengan baik oleh siswa. Namun kenyataannya banyak guru yang merasakan susahnya menyampaikan materi kepada siswa. Terlebih lagi bagi guru bahasa Jepang. Dimana tidak semua murid minat terhadap bahasa Jepang. Mungkin di kelas guru akan menemui murid yang senang bicara, murid yang diam dan pasif, dan murid yang tidak bisa diam membuat gaduh. Guru tidak dapat memaksakan seorang siswa dengan cara yang guru inginkan. Karena kemampuan anak dalam menangkap materi ajar tergantung dari gaya belajarnya. Menurut DePorter dan Hernacki (2003:112), gaya belajar adalah kombinasi dari menyerap, mengatur, dan mengolah informasi. Gaya belajar yang di jelaskan dalam quantum learning tersebut adalah:

\section{Visual}

Siswa yang memiliki gaya visual ini belajar melalui indera penglihatannya. Mereka akan belajar lebih cepat dengan tampilan visual seperti gambar, video, dan diagram. Dan cenderung melihat sikap, gerakan, dan bibir guru yang sedang mengajar. Kekurangan gaya belajar visual adalah kemungkinan susah mengingat informasi apabila di sampaikan dengan lisan. Saat mendapat petunjuk untuk melakukan sesuatu, biasanya akan melihat teman-teman lainnya baru kemudian dia sendiri yang bertindak. Tidak suka bicara didepan kelompok dan tak suka pula mendengarkan orang lain. Terlihat pasif dalam kegiatan diskusi.

\section{Auditori}

Siswa yang memiliki gaya auditori ini belajar melalui indera pendengarannya. Semua informasi hanya bisa diserap melalui pendengaran. Dapat mengulangi kembali dan 
menirukan nada, birama, dan warna suara. Siswa akan belajar lebih cepat mendengarkan apa yang guru katakan atau mampu mengingat dengan baik penjelasan materi yang didiskusikan oleh kelompok/ kelas. Biasanya pembicara yang fasih. Namun memiliki kesulitan untuk menyerap informasi dalam bentuk tulisan secara langsung.

\section{Kinestetik}

Siswa yang memiliki gaya belajar kinestetik ini belajar melalui bergerak, menyentuh, dan melakukan sesuatu yang memberikan informasi tertentu agar dia dapat meningatnya. Menanggapi perhatian fisik. Kekurangan gaya belajar kinestetik ini sulit berdiam diri atau duduk manis, selalu ingin bergerak. Seperti mengerjakan segala sesuatu yang memungkinkan tangannya aktif. Contoh: saat guru menerangkan pelajaran, dia mendengarkan sambil tangannya asyik menggambar. Siswa yang memiliki gaya belajar kinestetik ini menyukai praktek, permainan, dan aktifitas fisik.

Dalam mengajar terkadang guru hanya menggunakan 1 media yang hanya sesuai untuk 1 gaya belajar siswa. Sehingga siswa yang memiliki gaya belajar yang berbeda cenderung menjadi susah menerima pelajaran bahkan akan membuat malas belajar. Karena itu penulis akan mencoba membahas bagaimana mengajar dengan media ajar yang sesuai dengan 3 gaya belajar siswa.
Dengan memahami gaya belajar siswa maka guru akan mudah menentukan metode mengajar yang sesuai. Sehingga dengan metode mengajar dan penggunaan media ajar yang tepat maka siswa akan mudah menguasai materi pelajaran dengan gaya belajar masing-masing siswa.

Oleh karena itu penulis membuat artikel ini yang bertema "Penggunaan media ajar terhadap 3 gaya belajar siswa dalam pembelajaran bahasa Jepang”. Di sini, penulis akan berbagi pengalaman tentang mengajar dengan menggunakan variasi media ajar. membahas gaya belajar siswa dengan media ajar yang sesuai beserta metode pengajarannya.

\section{Metode penelitian}

Metode penelitian yang digunakan adalah deskriptif. Penelitian deskriptif adalah suatu metode penelitian yang ditujukan untuk menggambarkan fenomena-fenomena yang ada, yang berlangsung saat ini atau saat yang lampau. Penelitian ini tidak mengadakan manipulasi atau pengubahan pada variabelvariabel bebas, tetapi menggambarkan suatu kondisi apa adanya. Penggambaran kondisi bisa individual atau menggunakan angkaangka. (Sukmadinata, 2006:5)

Pada saat ini penulis belum melakukan penelitian secara kuantitatif. Penulis hanya mencoba mengajar dengan memperhatikan media ajar dan gaya belajar siswa. Kemudian 
mengamati dan melihat hasilnya. Ketika melihat nilai siswa yang bagus mungkin tidak bisa di sebut hasil dari metode mengajar yang baik. Penulis hanya merasakan murid menjadi lebih aktif dan antusias terhadap pelajaran bahasa Jepang. Setiap siswa yang belajar tentu saja akan menggunakan seluruh inderanya. Hanya saja ada bagian indera tertentu yang ketika di gunakan untuk belajar dapat dengan cepat menyerap dan mengolah informasi yang diterimanya. Dan tidak menutup kemungkinan ada siswa yang memiliki kombinasi gaya belajar.

\section{Langkah-langkah pembelajaran}

Dengan memperhatikan gaya belajar siswa maka penulis membuat media ajar yang sesuai. Media ajar yang sesuai untuk 3 gaya belajar adalah sebagai berikut:

1. Media ajar yang sesuai untuk gaya belajar visual (Belajar dengan cara melihat) adalah berupa gambar, grafik, ilustrasi, slide dan tulisan yang berwarna-warni. Sehingga penulis membuat slide power point yang menarik dengan gambar dan tulisan yang berwarna. Disamping itu siswa dengan gaya belajar visual juga akan memperhatikan gerak-gerik atau bahasa tubuh ketika guru menjelaskan. Secara tidak langsung guru dapat menjadi media ajar untuk siswa dengan gaya belajar visual. Mereka terkadang menyerap informasi dengan menatap lawan bicara. Oleh karena itu guru juga harus mempertahankan kontak mata ketika sedang mengajar.

2. Media ajar yang sesuai untuk gaya belajar auditori (belajar dengan cara mendengar) adalah berupa video, rekaman suara, dan pola bercerita dengan bunyi, irama, dan nada. Sehingga penulis menyiapkan suara dari CD atau video yang dapat di unggah dari youtube sesuai dengan materi ajar yang akan disampaikan.

3. Media ajar yang sesuai untuk gaya belajar kinestetik (belajar dengan bergerak, bekerja, dan menyentuh) adalah alat bantu peraga. Atau secara tidak langsung siswa dapat menjadi media ajar dengan melakukan gerakan fisik untuk memberikan contoh kosakata.

Tema materi yang pernah penulis ajarkan di kelas adalah salah satunya tentang kehidupan sehari-sehari. Berikut langkah langkah metode pengajaran yang pernah penulis lakukan.

a. Pada saat kegiatan pendahuluan penulis menyampaikan motivasi melalui video aktifitas. Sehingga untuk siswa yang memiliki gaya belajar visual dan gaya belajar auditori akan lebih termotivasi. 
Kemudian penulis memberikan pertanyaan untuk aktifitas yang telah siswa lakukan di pagi hari. Dan menyuruh siswa untuk menjawab dengan berdiri terlebih dahulu. Biasanya siswa yang memiliki gaya kinestetik akan menjawab dengan menggerakan tubuhnya. Dengan begitu siswa yang memiliki gaya belajar kinestetik akan termotivasi untuk belajar materi tersebut.

b. Setelah menyampaikan tujuan pembelajaran penulis melanjutkan ke materi. Penyampaian materi di mulai dengan kosakata kegiatan sehari-hari melalui slide gambar yang disertai dengan audio kosakata. Pada saat penyampaian kosakata melalui gambar dan suara dari CD mungkin akan sangat terasa membosankan untuk siswa yang memiliki gaya belajar kinestetik. Oleh karena itu siswa dengan gaya belajar kinestetik harus mengucap ulang kosakata dengan gerakan. Tentu saja saat itu seluruh siswa akan mengucap ulang dengan gerakan. Sehingga tanpa sadar siswa sedang menghapal kosakata beserta artinya. Contoh kosakatanya adalah: はを みがきます、かお を あらいます、みずを あびま す dan seterusnya.

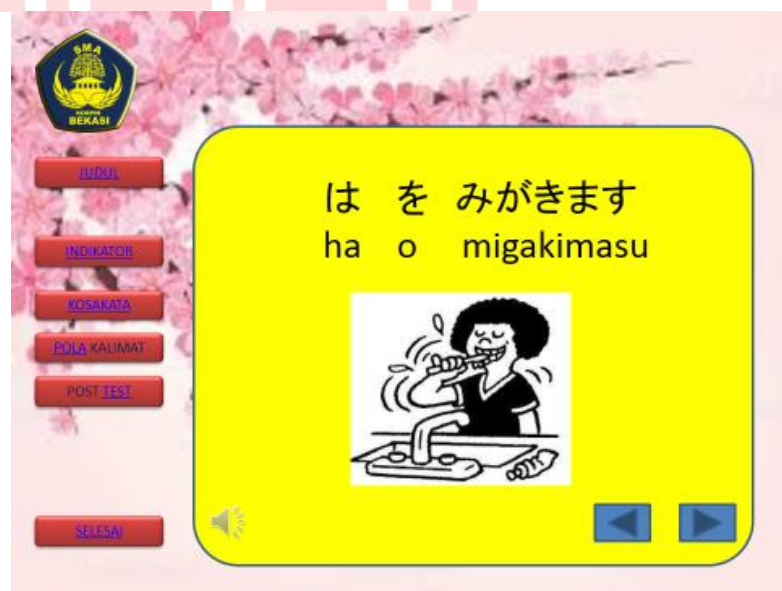

c. Untuk penyampaian pola kalimat pertama di sajikan dengan powerpoint. Pola kalimatnya adalah: keterangan waktu + kata kerja kegiatan. Contoh: あさ、かおを あらいます。Dan keterangan waktu + kata kerja kegiatan. +それから+ kata kerja kegiatan. 


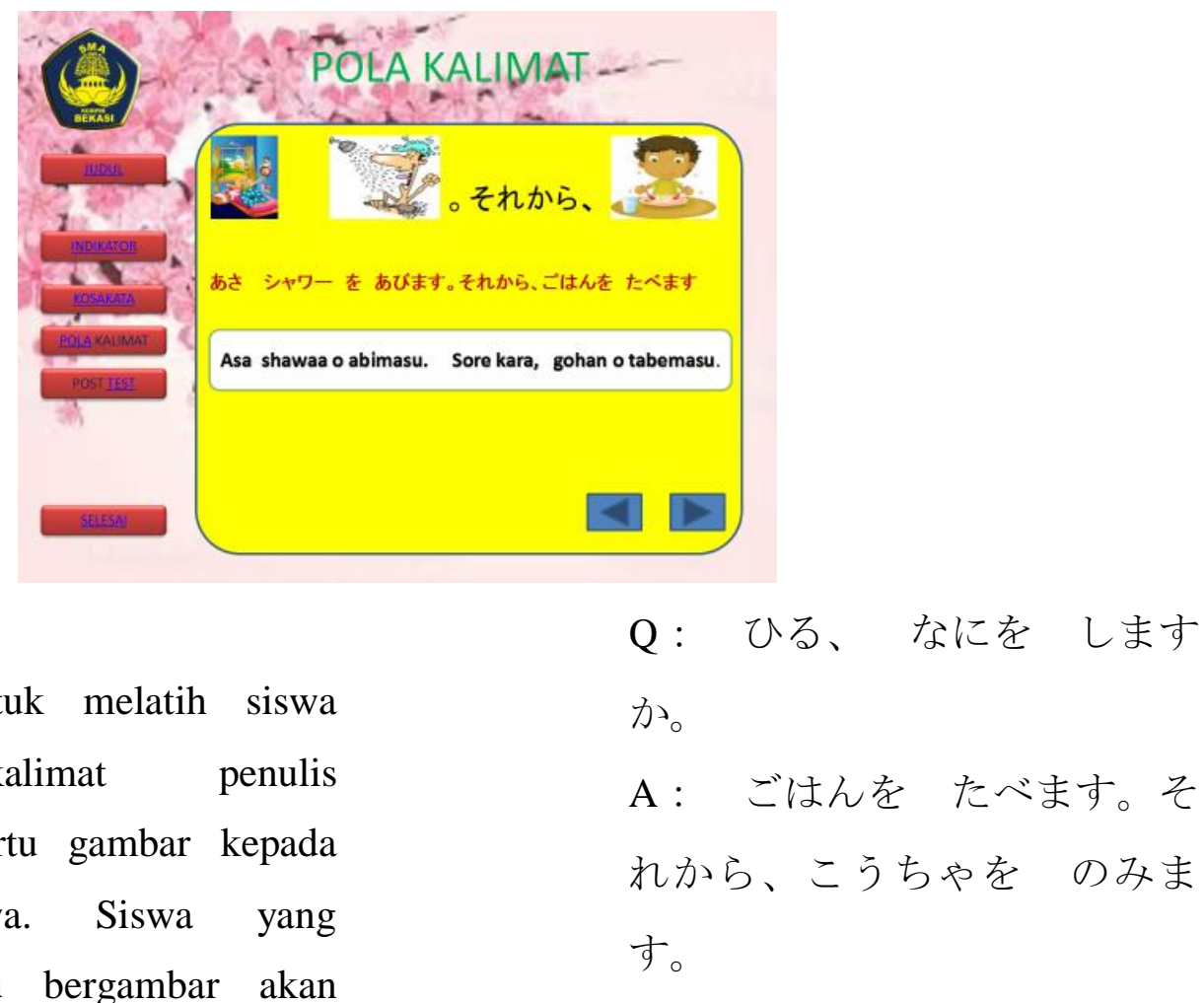

Selanjutnya untuk melatih siswa membuat kalimat penulis memberikan kartu gambar kepada beberapa siswa. Siswa yang mendapat kartu bergambar akan membuat kalimat dari kartu bergambar tersebut. Metode tersebut akan sesuai dengan gaya belajar visual. Kemudian penulis akan mengucapkan kalimat dalam bahasa Indonesia dan siswa menerjemahkan kalimat tersebut kedalam bahasa Jepang secara lisan dan tulisan. Metode tersebut akan sesuai dengan gaya belajar auditori maupun kinestetik.

d. Pada saat melatih percakapan, penulis mencontohkan sebuah percakapan kemudian siswa akan saling bertanya dan menjawab. Contoh percakapan:

$$
\begin{aligned}
& \mathrm{Q} \text { ： あさ、なにをしますか。 } \\
& \mathrm{A} \text { ： かおを あらいます。 }
\end{aligned}
$$

e. Setelah berlatih percakapan mereka akan melakukan game sekaligus menjawab quiz dengan peraturan sebagai berikut:

- Buat 3 kelompok! (kelompok A, B, dan C)

- Kelompok A bertugas menanyakan kegiatan sehari-hari kepada kelompok $\mathrm{C}$.

- Kelompok B bertugas memperagakan aktifitas kegiatan sehari-hari.(aktifitas di lihat dari kartu gambar yang sensei berikan)

- Kelompok C bertugas menjawab pertanyaan dari kelompok A dengan melihat gerakan kelompok B. 
- Setelah kelompok A bertanya

dan kelompok C menjawab,

Kelompok B menulis hasil tanya

jawab yang telah dilakukan.

Kemudian laporkan hasilnya di

depan kelas. f. Selesai bermain quiz penulis akan bertanya kepada siswa tentang kesulitan yang dihadapi.

g. Pada kegiatan penutup penulis akan memberikan tes yang soalnya ada di slide powerpoint.

Semuanya dilakukan tanpa melihat

buku. Sehingga siswa di tuntut untuk

menghapal kosakata.

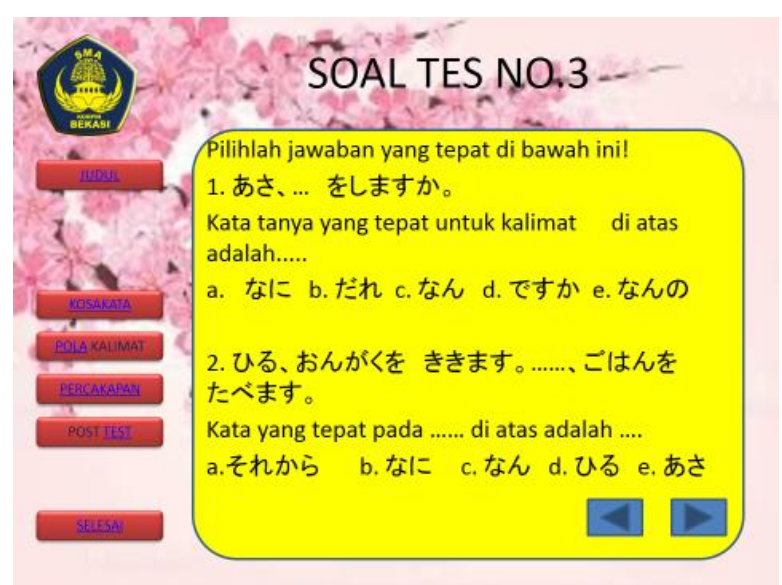

\section{Kesimpulan}

1. Menurut DePorter dan Hernacki (2003:112), gaya belajar adalah kombinasi dari menyerap, mengatur, dan mengolah informasi.

2. 3 jenis gaya belajar siswa yaitu: visual, auditori, dan kinestetik.

3. Karakteristik gaya belajar visual yaitu:

- Belajar melalui indera penglihatannya melalui tampilan visual seperti gambar, video, dan diagram.

- Cenderung melihat sikap, gerakan, dan bibir guru yang sedang mengajar.
- Susah mengingat informasi apabila di sampaikan dengan lisan.

- Saat mendapat petunjuk untuk melakukan sesuatu, biasanya akan melihat teman-teman lainnya baru kemudian dia sendiri yang bertindak.

- Terlihat pasif dalam kegiatan diskusi.

4. Karakteristik gaya belajar auditori yaitu: - Belajar melalui indera pendengarannya. Semua informasi hanya bisa diserap melalui pendengaran.

- Dapat mengulangi kembali dan menirukan nada, birama, dan warna suara. 
- Belajar lebih cepat mendengarkan apa yang guru katakan atau mampu mengingat dengan baik penjelasan materi yang didiskusikan oleh kelompok/ kelas.

- Biasanya pembicara yang fasih.

- Memiliki kesulitan untuk menyerap informasi dalam bentuk tulisan secara langsung.

5. Karakteristik gaya belajar kinestetik yaitu:

- Belajar melalui bergerak, menyentuh, dan melakukan sesuatu yang memberikan informasi tertentu agar dia dapat meningatnya.

- Menanggapi perhatian fisik.

- Sulit berdiam diri atau duduk manis, selalu ingin bergerak. Seperti mengerjakan segala sesuatu yang memungkinkan tangannya aktif. Contoh: saat guru menerangkan pelajaran, dia mendengarkan sambil tangannya asyik menggambar.

- Menyukai praktek, permainan, dan aktifitas fisik.

6. Media ajar yang sesuai untuk gaya belajar visual (Belajar dengan cara melihat) adalah berupa gambar, grafik, ilustrasi, slide dan tulisan yang berwarna-warni.

7. Media ajar yang sesuai untuk gaya belajar auditori (belajar dengan cara mendengar) adalah berupa video, rekaman suara, dan pola bercerita dengan bunyi, irama, dan nada.

8. Media ajar yang sesuai untuk gaya belajar kinestetik (belajar dengan bergerak, bekerja, dan menyentuh) adalah alat bantu peraga.

9. Media ajar yang dapat menarik semua perhatian siswa diharapkan dapat menumbuhkan motivasi dan minat siswa untuk belajar bahasa Jepang.

\section{Daftar Pustaka}

[1] De Porter, Bobbi. 2003. Quantum Learning Membiasakan Belajar Nyaman dan Menyenangkan. Bandung: Kaifa

[2] http://www.edukiper.com/2016/09/caramengembangkan-potensi-pembelajarvisual/ (diakses pada 8 Maret 2017)

[3] http://belajarpsikologi.com/macammacam-gaya-belajar/ (diakses pada 13 Maret 2017)

[4] http://penjualmimpi.blogspot.co.id/2014/09/jenisjenis-metode-penelitian-beserta.html (diakses pada 29 Mei 2017) 